\title{
Effects of Intravenous Fructose Infusion on Sodium Handling and Peripheral Vascular Tone in Pre-Hypertensive Subjects
}

\author{
Claudio Borghi, Stefano Boschi* , Francesco Vittorio Costa, Stefano Bacchelli, \\ Daniela Degli Esposti, Massimo Piccoli, Maurizio Capelli** ${ }^{* *}$ and Ettore Ambrosioni
}

\begin{abstract}
The hemodynamic and humoral effects of i.v. fructose infusion and a control infusion were studied in 12 borderline hypertensive patients according to a single-blind, cross-over, randomized protocol. Fructose infusion decreased urinary sodium excretion and significantly increased plasma insulin, plasma $\mathrm{Na}^{+} / \mathrm{K}^{+}$ ATPase inhibitory activity, and forearm arterial and venous tone $(+13 \%)$, the last of which was not observed during the control infusion $(-2.5 \%)$. Levels of ANF and PRA in plasma were not altered by either infusion. We conclude that the sodium retention caused by acute $i . v$. fructose loading could be related to the increase in plasma insulin levels, which may directly affect individual susceptibility to sodium by enhancing sodium reabsorption at renal tubules. This sodium retention could contribute to the release of a plasma $\mathrm{Na}^{+}$-pump inhibitor apparently unrelated to extracellular volume expansion and potentially responsible for the early peripheral vascular involvement found in hypertension-prone men. (Hypertens Res 1994; 17: 239-242)
\end{abstract}

Key Words: fructose, sodium, borderline hypertension

Recent reports indicate that Sprague-Dawley rats on a fructose-enriched diet develop a progressive increase in arterial blood pressure apparently unrelated to changes in body weight or in the reninangiotensin-aldosterone system $(1,2)$. The mechanisms responsible for this increase are still poorly understood, and the hyperinsulinemia that occurs when animals are fed a high-fructose diet may be involved $(2,3)$. A role for insulin metabolism in the pathogenesis of arterial hypertension has been repeatedly suggested, and hyperinsulinemia and insulin resistance have been reported in experimental (1) and human hypertension (4). In particular, by reduction of urinary sodium excretion $(5,6)$ insulin could contribute to the development of sodium-dependent hypertension via promotion of extracellular volume expansion or interference with the neurohumoral pathway, or both (1). More recently, plasma insulin levels were found to directly affect the salt-dependent increase in blood pressure in Dahl rats (7). To further clarify this latter issue, we studied the effects of fructose infusion on some humoral mechanisms thought to be involved in the development of salt-related hypertension (8). In particular, the present study was done to investigate the relationship between fructose loading, sodium balance, and insulin release in young patients with borderline hypertension.

\section{Materials and Methods}

The subjects were 12 young (age $24 \pm 4$ years) borderline hypertensive patients ( 9 men and 3 women) with normal plasma renin activity. Secondary hypertension was excluded by physical and laboratory examination. All the patients were free of antihypertensive medications and all kept to a constant daily sodium intake of $100 \mathrm{mmol}$ for 7 days before the study. Patients were studied in a metabolic ward at a constant room temperature of $24^{\circ} \mathrm{C}$ and after 30 minutes of rest in a recumbent position. The responses to a 2-hour i.v. infusion of high-dose isotonic fructose $(0.25 \mathrm{ml} / \mathrm{min} / \mathrm{kg} \mathrm{b.w}$. FRUCT $)$ and lowdose isotonic fructose $(0.025 \mathrm{ml} / \mathrm{min} / \mathrm{kg} \mathrm{b.w}$. CONTROL) were measured in a single-blind, randomized, crossover study. During the study the carbohydrate and sodium intake were kept unchanged and the two tests were done 48 hours apart. The study protocol was approved by the Ethical Committee of the University of Bologna and informed consent was obtained from each patient before inclusion in the trial. Heart rate, and systolic, diastolic, and mean blood pressures were measured with an automatic device (Sentry Automated Screening Devices, Costa Mesa, CA) and the values reported are means of five consecutive measurements. Fore-

From the Third Department of Internal Medicine, ${ }^{*}$ Department of Clinical Pharmacology and Therapeutics, ** Department of Clinical Chemistry, University of Bologna, Bologna, Italy.

Address for Reprints: Claudio Borghi MD, Clinica Medica III ${ }^{\circ}$, Policlinico S.Orsola, Via Massarenti 9, 40138 Bologna, Italy.

Received February 14, 1994; accepted in revised form July 7, 1994. 
arm blood flow (FBF), vascular resistance (FVR) and venous distensibility were determined by venous occlusion plethysmography with a singlestrand mercury-in-silastic strain gauge, according to a standard method $(9,10)$. The venous volume at a congesting pressure of $30 \mathrm{mmHg}$ above the minimum occlusion pressure was derived for each subject and expressed as $\mathbf{V V}_{30}$. Plasma renin activity (PRA), plasma aldosterone, and plasma insulin were measured by radioimmunoassay. Plasma and urinary sodium and potassium were measured by flame photometry. Levels of atrial natriuretic factor (ANF) in plasma were determined by commercial radioimmunoassay (Amersham ANP R.I.A. System, Amersham Radiochemical, Buckinghamshire, U.K.) after plasma purification on Bond-Elut C-18 disposable columns (Analytichem International, Harbor City, CA). Levels of an endogenous inhibitor of $\mathrm{Na}^{+} / \mathrm{K}^{+}$ATPase, whose biochemical characteristics have been previously published (11), were measured in plasma by enzyme-coupled assay as described elsewhere in detail $(9,10)$. To exclude the interference of a fructose-induced rise in plasma lipid concentration on the increase in $\mathrm{Na}^{+} / \mathrm{K}^{+}$ ATPase inhibitory activity (12), 10 boiled plasma extracts with high levels of $\mathrm{Na}^{+}$-pump inhibitor were assayed before and after extraction with a hexane and hexane/ $\mathrm{CHCl}_{3}(50 / 50)$, mixture to remove lipids from the samples, and the results were compared.

The protocol was as follows. Immediately before infusion, a baseline blood sample was obtained from an antecubital vein. Then baseline blood pressure and forearm hemodynamics were determined. The measurements were repeated and blood was sampled again after $120 \mathrm{~min}$ of fructose infusion. The rates of urinary excretion of sodium and potassium during the $24 \mathrm{~h}$ after fructose loading were calculated both cumulatively ( 0 to $24 \mathrm{~h}$ ) and in two separate specimens defined as immediate (0 to $2 \mathrm{~h}$ ) and delayed ( 2 to $24 \mathrm{~h}$ ). Results are expressed as mean \pm SD. Two-way analysis of variance for cross-over- design experiments was used to compare the effects of fructose loading on normally distributed variables. In the presence of significant values of " $f$ ", the Least Significant Difference test was applied and $p$ values $>0.05$ were rejected. The paired Student's " $t$ " test was used to compare baseline characteristics of patients.

\section{Results}

Cumulative urinary sodium excretion was significantly lower during FRUCT loading than during CONTROL $\quad(2.22 \pm 0.8$ vs. $2.82 \pm 0.6$ $\mu \mathrm{mol} / \mathrm{min} / \mathrm{kg} ; p<0.05)$ and the difference resulted mainly from a lesser immediate natriuresis $(0.30 \pm$ $0.07 v s .0 .45 \pm 0.1 \mu \mathrm{mol} / \mathrm{min} / \mathrm{kg} ; p<0.05)$. Delayed sodium excretion was also lower, but the difference was not statistically significant $(1.92 \pm 0.5$ vs. 2.4 $\pm 0.8 \mu \mathrm{mol} / \mathrm{min} / \mathrm{kg}$; N.S.) because of the small sample size. The effects of two-hour FRUCT and CONTROL infusions on the hormonal and hemodynamic variables are summarized in Table 1. Fructose infusion caused a significant increase in plasma levels of endogenous $\mathrm{Na}^{+} / \mathrm{K}^{+}$ATPase inhibitor. Such an increase was detected in 10 of the 12 patients. The increase was apparently independent of changes in plasma lipid concentration, since it was not prevented, and was even magnified by extraction of plasma lipids from the 10 samples showing a rise in $\mathrm{Na}^{+} / \mathrm{K}^{+}$ATPase inhibitor (non-extracted $53 \pm 19 v s$. extracted $63 \pm 17 ; p<0.005$ ). Conversely, levels of ANF in plasma were unchanged after both FRUCT and CONTROL infusions as were PRA, plasma aldosterone, and hematocrit. As expected, plasma insulin increased only after FRUCT and no significant relationships were found between changes in insulin and the hemodynamic and humoral responses to fructose challenge. Arterial blood pressure was unaffected by either infusion, but a mean increase in FVR and a decrease in $\mathrm{VV}_{30}$ was observed after FRUCT only. These occurred in 8 of the 10 patients in whom plasma

Table 1. Effects of Fructose and Control Infusions on Hemodynamic and Humoral Variables in Borderline Hypertensive Patients

\begin{tabular}{lcccc}
\hline & Baseline & Control & Baseline & Fructose \\
\hline Systolic BP (mmHg) & $131.5 \pm 8$ & $128.3 \pm 10$ & $132.5 \pm 9$ & $134.5 \pm 7$ \\
Diastolic BP (mmHg) & $75.4 \pm 7$ & $73.9 \pm 7$ & $75.0 \pm 6$ & $72.2 \pm 5$ \\
Heart rate (b/min) & $68.4 \pm 7$ & $64.9 \pm 6$ & $68.2 \pm 7$ & $62.4 \pm 7$ \\
FBF (ml/min/100 ml) & $3.7 \pm 1$ & $3.6 \pm 1$ & $3.6 \pm 1$ & $3.1 \pm 0.9$ \\
FVR (units) & $28.9 \pm 5$ & $28.0 \pm 5$ & $28.3 \pm 5$ & $33.3 \pm 4^{* *}$ \\
VV 30 (ml/100 ml) & $1.7 \pm 0.3$ & $1.7 \pm 0.3$ & $1.7 \pm 0.3$ & $1.5 \pm 0.3^{*}$ \\
PRA (ng/ml/h) & $1.8 \pm 1$ & $1.6 \pm 1$ & $1.8 \pm 1$ & $1.4 \pm 1$ \\
Pl. Aldosterone (pg/ml) & $261.0 \pm 67$ & $162.0 \pm 56$ & $223.0 \pm 80$ & $140.0 \pm 86$ \\
ANF (pg/ml) & $22.9 \pm 9$ & $23.1 \pm 8$ & $23.4 \pm 8$ & $24.7 \pm 9$ \\
Na ${ }^{+}$ATPase inhibition $(\%)$ & $37.5 \pm 8$ & $35.1 \pm 9$ & $35.0 \pm 1$ & $47.5 \pm 11^{* *}$ \\
Plasma glucose (mg/dl) & $85.3 \pm 11$ & $81.2 \pm 9$ & $87.4 \pm 8$ & $108.6 \pm 20^{* *}$ \\
Plasma insulin (U/ml) & $12.1 \pm 3$ & $11.6 \pm 5$ & $11.4 \pm 3$ & $17.6 \pm 6^{* *}$ \\
Hematocrit (\%) & $45.4 \pm 3$ & $45.1 \pm 3$ & $45.1 \pm 3$ & $44.0 \pm 2$ \\
\hline
\end{tabular}

* ${ }^{* *} p<0.5, p<0.05$ compared to first baseline value. 
$\mathrm{Na}^{+} / \mathrm{K}^{+}$ATPase inhibitory activity increased in response to the infusion.

\section{Discussion}

The present study shows that i.v. fructose infusion has an antinatriuretic effect in borderline hypertensive patients. This effect seems to be related to an increase in plasma insulin levels, whose ability to promote sodium reabsorption has been recently confirmed in salt-sensitive animals with sodium retention and an increase in blood pressure during insulin infusion. These data suggest that plasma insulin, sodium, and high blood pressure are directly related (7). Since human borderline hypertension has been classified among the salt-related conditions (13), the present data largely support the experimental observations on insulin and sodium handling and suggest that plasma insulin is very much involved in the activation of mechanisms that contribute to the development of salt-related hypertension. Despite the sodium retention, we found no concomitant increase in blood pressure in response to fructose infusion. Since a pressor increase after fructose overload has been reported in animals on a fructose-enriched diet $(1,2)$, we believe that the acute nature of the i.v. fructose loading in the present study did not allow for a sustained hyperinsulinemia or for an adequate change in extracellular volume, or both. Indeed, the hypertensive effects of insulin have been observed only in response to continuous insulin infusion (7) or, as in the study by Hwang et al. (2), in a setting where high oral fructose was associated with indirect evidence of extracellular volume overload (suppression of the renin-angiotensin-aldosterone system and an increase in ANF). In the present study, the occurrence of sodium retention and forearm vasoconstriction without pressor changes suggests that insulin may increase blood pressure through an initial sodium-vasoconstriction pathway. The pathophysiological factor linking such a pathway to high blood pressure could be the plasma $\mathrm{Na}^{+} / \mathrm{K}^{+}$ATPase inhibitor. The levels of this inhibitor increased significantly during fructose loading despite the lack of volume expansion, which suggests that such a humoral factor is relatively independent of changes in circulating volume distribution. This observation is in agreement with the data of Hamlyn et al. (14) who reported a sudden increase in plasma levels of $\mathrm{Na} / \mathrm{K}$ ATPase inhibitor not associated with changes in plasma volume during the early antinatriuretic phase of DOCA-salt hypertension. However, since most studies have related the release of a $\mathrm{Na} / \mathrm{K}$ ATPase inhibitor to extracellular volume expansion (8) we would like to provide some tentative explanations for the release of a $\mathrm{Na} / \mathrm{K}$ ATPase inhibitor without changes in plasma volume. First, some degree of volume expansion may have occurred early in the fructose infusion when we did not measure any index of plasma overloading. Alternatively, the degree of volume expansion achieved in response to fructose infusion (reduction of hematocrit from $45.1 \%$ to $44.0 \%$ ) even if not statistically significant, may have been sufficient to cause the release of a $\mathrm{Na} / \mathrm{K}$ ATPase inhibitor. Finally, plasma insulin per $s e$ or the increase in sympathetic activity that follows hyperinsulinemia (15) may have been sufficient to stimulate the release of an endogenous $\mathrm{Na} / \mathrm{K}$ ATPase inhibitor. Indeed, an increase in the level of $\mathrm{Na} / \mathrm{K}$ ATPase inhibitor, and an increase in inhibitory activity have been reported in some settings not associated with volume expansion, such as water depletion (16), elevation of intracerebral sodium levels (17), and intracisternal administration of the dopamine-receptor agonist pergolide (18).

The increase in the level of the $\mathrm{Na}^{+}$-pump inhibitor in plasma is specific in nature: the extraction of samples with hexane to remove the lipids and prevent their interference in the enzyme-coupled assay increased the degree of $\mathrm{Na}^{+} / \mathrm{K}^{+}$ATPase inhibition. The vasoconstrictive properties attributed to $\mathrm{Na}^{+}$/ $\mathrm{K}^{+}$ATPase inhibitors $(8)$ could explain the increase in forearm vascular resistance and venous tone observed in the present study during fructose infusion. The vasoconstrictive effects of $\mathrm{Na} / \mathrm{K}$ ATPase inhibition seem to be stronger than the reported vasodilating activity of hyperinsulinemia (19), which is critically dependent on the indirect activation of $\mathrm{Na} / \mathrm{K}$ ATPase in the vessel wall (20). We speculate that the brisk reduction in sodium excretion observed during acute fructose infusion promoted the release into the bloodstream of $\mathrm{Na}^{+} / \mathrm{K}^{+}$ATPase inhibitor to counteract sodium retention by mechanisms that do not necessarily cause an immediate natriuretic response (8). A similar prompt increase in endogenous $\mathrm{Na}^{+} / \mathrm{K}^{+}$ATPase inhibitor occurring without a significant increase in blood pressure and a with fall in plasma levels of ANF has been reported to occur during the early antinatriuretic phase of DOCA-induced hypertension (14). Interestingly, the lack of ANF response reported by Hamlyn (14) and confirmed by our results in a different setting (21), could contribute to the rise in plasma $\mathrm{Na}^{+}$-pump inhibitor by precluding the described inhibitory influence of stimulated ANF on the secretion of such plasma factors $(14,21,22)$.

In conclusion, our present data support the hypothesis that the increase in plasma levels of insulin that follows intravenous fructose infusion promotes renal sodium reabsorption and peripheral vasoconstriction, and thereby contributes to the development of salt-sensitive hypertension. We also suggest that insulin may act through a sodium-vasoconstriction pathway modulated by an endogenous $\mathrm{Na}^{+}$-pump inhibitor, which is released into the bloodstream when renal sodium reabsorption is high, and is responsible for the early peripheral vascular abnormalities found in borderline hypertensive patients before the development of stable hypertension.

\section{References}

1. Hwang I-S, Ho H,Hoffman BB, Reaven GM: Fructose-induced insulin resistance and hypertension in rats. Hypertension 1987; 10: 512-516.

2. Hwang I-S, Huang W-C, Wu J-N, Shian LR, Reaven 
GM: Effects of fructose-induced hypertension on the renin-angiotensin-aldosterone system and atrial natriuretic factor. Am J Hypertens 1989; 2: 424-427.

3. Sleder J, Chen Y-DI, Cully MD, Reaven GM: Hyperinsulinemia in fructose-induced hypertriglyceridemia in the rat. Metabolism 1980; 29: 303-305.

4. Ferranini E, Buzzigoli G, Bonadonna R, et al: Insulin resistance in essential hypertension. $N$ Engl $\mathrm{J} \mathrm{Med}$ 1987; 317: 350-357.

5. De Fronzo R, Goldberg M, Agus Z: The effects of glucose and insulin on renal electrolyte transport. $J$ Clin Invest 1976; 58: 83-90.

6. De Fronzo R, Cooke C, Andres R, Faloona G, Davis P: The effects of insulin on renal handling of sodium, potassium, calcium and phosphate in man. $J$ Clin Invest 1975; 55: 845-855.

7. Tomiyama $\mathrm{H}$, Kushiro $\mathrm{T}$, Abeta $\mathrm{H}$, et al: Blood pressure response to hyperinsulinemia in salt-sensitive and salt-resistant rats. Hypertension 1992; 20: 596-600.

8. De Wardener HE, Clarkson EM: Concept of natriuretic hormone. Physiol Rev 1985; 65: 659-759.

9. Borghi C, Boschi S, Costa FV, Munarini A, Mussi $\mathrm{A}$, Ambrosioni E: Importance of plasma renin activity suppression and venous distensibility on pressor and natriuretic response to intravenous salt load in borderline hypertension. Am J Hypertens 1988; 1: 294-297.

10. Borghi C, Boschi S, Costa FV, Ambrosioni E: Pattern of peripheral venous response to volume expansion in borderline systemic hypertension. Am J Cardiol 1990; 66: 597-602.

11. Boschi S, Borghi C, Munarini A, et al: Purification of a $\mathrm{Na}^{+} / \mathrm{K}^{+}$ATPase inhibitor from borderline hypertensive plasma. Bioch Biophys Res Comm 1990; 169: $360-368$.

12. Tamura $M$, Kuwano $H$, Kinoshita $T$, Inagami $T$ : Identification of linoleic and oleic acid as an endogeneous $\mathrm{Na}^{+} / \mathrm{K}^{+}$ATPase inhibitor from acute volume expanded hog plasma. J Biol Chem 1985; 260: 9672-9677.

13. Borghi C, Boschi S, Costa F.V., Ambrosioni E: De- terminants of acute salt-sensitivity in hypertensionprone men. J Hypertens 1991; 9 (suppl.6): S318-S319.

14. Hamlyn JM: Increased levels of a humoral digitalislike factor in deoxycorticosterone acetate-induced hypertension in the pig. $J$ Endocrinol 1989; 122: 409-420.

15. Anderson EA, Hoffman RP, Balon TW, Sinkley CA, Mark AL: Hyperinsulinemia produces both sympathetic neural activation and vasodilatation in humans. J Clin Invest 1991; 87: 2246-2252.

16. Wellar RM, Adam WR: Water depletion, not oral sodium loading, increases levels of sodium, potassium-dependent ATPase inhibitor in rat plasma. Clin Sci 1987; 73: 87-92.

17. Jandhyala BS, Ansari AF: Elevation of sodium levels in the cerebral ventricles of anesthetized dogs triggers the release of an inhibitor of ouabain-sensitive sodium, potassium ATPase into the circulation. Clin Sci 1986; 70: 103-110.

18. Jandhyala BS, Lokhadwaka MF, Kivlighn SD, Ansari AF, De Feo ML: Intracisternal administration of pergolide, a dopamine receptor agonist, triggers the release of an inhibitor of ouabain-sensitive sidium, potassium-dependent adenosine triphosphatase and enhances vascular reactivity in anesthetized dogs. Clin Sci 1987; 73: 183-188.

19. Ferranini E, Natali A: Insulin resistance and hypertension: connections with sodium metabolism. Am J Kidney Dis 1993; 21 (suppl.2): 37-42.

20. Grinstein S, Rothstein A: Mechanisms of regulation of the $\mathrm{Na}^{+}: \mathrm{H}^{+}$exchanger. J Membr Biol 1986; 90: 1-12.

21. Borghi C, Boschi S, Costa FV, Ambrosioni E: Atrial natriuretic factor modulates the plasma levels of a $\mathrm{Na}^{+} / \mathrm{K}^{+}$ATPase inhibitor in volume expanded borderline hypertension. Am J Hypertens 1991; 4: 618622 .

22. Crabos M, Ausiello DA, Haupert GT, Cantiello HF: Atrial natriuretic peptide regulates release of a $\mathrm{Na}^{+} / \mathrm{K}^{+}$ATPase inhibitor from rat brain. Am J Physiol 1988; 254: F912-F917. 